\title{
Surgical revolution vs surgical evolution
}

\section{Eye (2007) 21, 155. doi:10.1038/sj.eye.6702247}

There can be revolutions in treatment, and there can be evolutions. When a piece of research establishes that a disease is treatable, a revolution occurs because suddenly diagnosis of the disease becomes vital.

This happened over 10 years ago when the CRYO-ROP study reported that treating ROP was worthwhile. In this study, the treatment 'threshold' was set at a level where the risk of blindness untreated was $50 \%$.

In 2003, revised indications for treatment were published, following the Early Treatment of ROP study. ${ }^{1}$ Now, the treatment 'threshold' was set at a $15 \%$ risk of blindness.

One of the reasons why earlier treatment has become popular is that cryotherapy has gradually been replaced by diode laser of the retina. Although there was a large multi-centre study on outcome (where either diode laser or cryotherapy could be used), the comparative studies between cryotherapy and diode laser treatment have been rather small. The replacement of one by the other has been an evolution rather than a revolution, and is almost complete, as the paper on page Insert the page number and title of the paper here shows.

This is rather similar to the way that extracapsular cataract surgery replaced intracapsular cataract surgery, and then was itself replaced by phakoemulsification surgery. Hardly any prospective randomized trials, and only small ones at that.

Staunch advocates of evidence-based medicine may roll their eyes up in horror at the behaviour of ophthalmic surgeons, but I find it difficult to regard this gradual replacement as wrong. The precise moment as to when the premature infant's retina should be treated was never set with any great rigour, from the point of view of the risks $v s$ benefits, or blindness $v s$ risk of mortality. One of the reasons the initial (rather high) threshold for treatment was chosen as a $50 \%$ risk of blindness was the necessity of getting a statistically viable result in the trial. For several reasons, refinements of treatment cannot
RMC Gregson

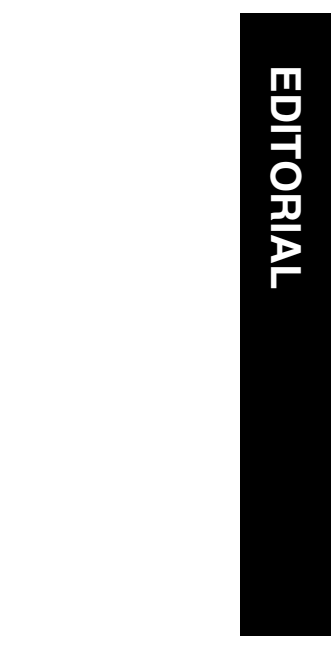

be subject to similar randomized trials. One of these is the fact that the more mild treatment is often given at an earlier stage because the risks of the procedure are lower. Another is that many ophthalmologists have strongly held views and would not contemplate allowing their patients to be randomized in a trial. Differences in the incidence of ROP from country to country are large, ${ }^{2}$ reflecting differences in neonatal care, provision of medical services, and screening. These differences must also exist, to a lesser degree, within nations, making multi-centre trials impossible if small effects are being sought.

Personally, I believe that the way ophthalmologists moved from one operation to the other, with so few prospective studies, is actually also the right way. Early on, phakoemulsification was incompletely developed, the surgeons not fluent in the technique, and the hardware not as sophisticated as it now is. A prospective study at the outset would have certainly shown phakoemulsification in a poor light. It would have been unlikely to be introduced, and patients would have been deprived of the undoubted benefits. Later on, the procedure techniques honed, any randomized trial would be unethical.

There is also a definite Darwinism about these processes: not all ophthalmologists may agree about whether the newer treatment is better than the established one, but newer ophthalmologists embraced diode laser for ROP (or phakoemulsification for that matter) and the older ophthalmologists, who did not, gradually retire and are removed from the gene pool.

\section{References}

1 Early Treatment for Retinopathy of Prematurity Cooperative Group. Results of the Early Treatment for Retinopathy of Prematurity Randomized Trial. Arch Ophthalmol 2003; 121: 1684-1694.

2 Gilbert C, Fielder A, Gordillo L, Quinn G, Semiglia $\mathrm{R}$, Visintin $\mathrm{P}$ et al. Characteristics of infants with severe retinopathy of prematurity in countries with low, moderate, high levels of development. Implications for screening programs. Pediatrics 2005; 115(5): e518-e525.
Department of Ophthalmology, University Hospital, Queen's Medical

Correspondence:

RMC Gregson,

Department of

Ophthalmology,

Nottingham NG7 2UH, UK

Tel: + 441159249924 ext. 42679;

Fax: +44 1159709749 .

E-mail: richard.gregson@ qmc.nhs.uk Centre, Nottingham, UK 